\title{
Early warnings from automatic milk yield monitoring with online synergistic control
}

\author{
T. Huybrechts, ${ }^{1}$ K. Mertens, J. De Baerdemaeker, B. De Ketelaere, and W. Saeys \\ BIOSYST-MeBioS, Katholieke Universiteit Leuven, Kasteelpark Arenberg 30, 3001 Leuven, Belgium
}

\begin{abstract}
Sensors play a crucial role in the future of dairy farming. Modern dairy farms today are equipped with many different sensors for milk yield, body weight, activity, and even milk composition. The challenge, however, is to translate signals from these sensors into relevant information for the farmer. Because the measured values for an individual cow show nonstationary behavior, the concepts of statistical process control, which are commonly used in industry, cannot be used directly. The synergistic control concept overcomes this problem by on-line (real-time) modeling of the process and application of statistical process control to the residuals between the measured and modeled values. In this study, the synergistic control concept was developed and tested for early detection of anomalies in dairy cows based on detection of shifts in milk yield. Compared with the combination of visual observation and milk conductivity measurements, the developed strategy had a sensitivity of $63 \%$ for detecting clinical mastitis. Consequently, this technique could have added value on many farms, as it extracts practical information out of inexpensive data that are already available. As it can be easily extended to other measured parameters, the technique shows potential for early detection of other nutrition and health problems.
\end{abstract}

Key words: early detection, milk yield, mastitis, statistical process control, synergistic control

\section{INTRODUCTION}

The current trend is toward larger dairies as a means of maintaining profitability; however, the availability of affordable skilled labor becomes more of a production-limiting factor (Bewley, 2010). In this changing scene, modern dairy farms have 2 options for high-tech milking: a high-capacity parlor (milking many cows per hour) or automatic milking systems (AMS) that replace manual labor. As well as the main goal of milk-

Received April 10, 2013.

Accepted February 24, 2014.

${ }^{1}$ Corresponding author: Tjebbe.Huybrechts@biw.kuleuven.be ing the cow, milking provides an opportunity 2 or 3 times each day to gather data from cows for virtual use in signaling emerging health problems. In farms with an AMS, there is generally no contact between the farmer and the cow during milking, whereas in farms where cows are milked in a high-capacity parlor, the farmer still has some time to visually detect problems (Hogeveen and Ouweltjes, 2003). However, to milk as many cows as possible in a given timeframe, the time spent per cow decreases significantly, causing little or no time available for the farmer to observe health status or other conditions of the cows.

This development has created a need for sensors and management support systems to detect health problems on farms with AMS and on large farms in general (Ordolff, 2001). Such automatic monitoring systems, which complement or even replace the human senses, can limit the economic loss associated with diseases, and they play an important role in fulfilling the needs of a sustainable dairy farm (Nielsen et al., 2005; Chagunda et al., 2006; Brandt et al., 2010). However, the interpretation of the measured signals is difficult because of the uniqueness of every cow (Nielsen et al., 2005; Chagunda et al., 2006). The observed variability in the signals can be categorized as inter- and intrasubject variability. The former refers to the variation between signals of different cows, whereas the latter refers to the variability in the signals obtained for one cow over a period of time and may be induced by a changing environment (Mertens et al., 2011).

A disadvantage of existing models and systems for the detection of mastitis and illness based on data of widely used sensors (e.g., milk yield, electrical conductivity, and activity) is the high number of false alarms, which hampers their practical application (de Mol and Ouweltjes, 2001; Rutten et al., 2013). In existing systems, high sensitivity (>80\%) is often combined with low specificity and vice versa (Rutten et al., 2013). Only a model based on the detection of L-lactate dehydrogenase (Chagunda et al., 2006) and the Herd Navigator milk analyzer (DeLaval, Tumba, Sweden) seemed to perform well (80-82\% sensitivity and $98 \%$ specificity). Consequently, successful management of livestock still largely depends on the skills, experience, 
and assessment capability of the stockman (Mertens et al., 2011). The key to fully exploit these available data for improving process performance and product quality lies in understanding the information contained in the variation of the process (Deming, 1986). Variation can be interpreted as a change in the process but can also obscure a real change (de Vries and Conlin, 2003).

Statistical process control (SPC) is widely used in industry to understand and decrease process variability and to pinpoint abnormal or special-cause variation (de Vries and Conlin, 2003; De Ketelaere et al., 2011; Mertens et al., 2011). The major tool in SPC is the control chart (CC), first developed in the 1920s by Walter E. Shewhart (Shewhart, 1931; Montgomery, 2009). Control charts, and SPC in general, have become a main component in quality assurance programs in industrial production.

A review by Mertens et al. (2011) showed increasing interest in SPC in animal production, with a focus on poultry, dairy, and swine production. Yet, application of $\mathrm{CC}$ in animal production is still marginal, and papers on the practical benefits of implemented $\mathrm{CC}$ are not yet available (de Vries and Reneau, 2010). The cause is multifaceted. A first difficulty lies in the fact that $\mathrm{SPC}$ is bound to 3 assumptions of the statistical model underlying the calculations: The data used in CC (1) have to be stationary, (2) have to be independent, and (3) have to follow the distribution function associated with the CC used. In practice, $85 \%$ of raw process data violate these basic assumptions of $\mathrm{CC}$ (Alwan and Roberts, 1995). Most livestock process data also violate these assumptions (De Ketelaere et al., 2011). Apart from this technical challenge, potential users still have to become familiar with and convinced of the potential of the technique (de Vries and Reneau, 2010).

The crucial part for lifting SPC from the potential level to direct practical relevance is contained in a real-time approach (Mertens et al., 2011). To support daily livestock management, a CC should detect process aberrations at the start. As such, management can be adapted in a timely way, reducing production losses and keeping product quality at a high and constant level.

To be able to use CC in an ad hoc or online way, Mertens and colleagues (Mertens et al., 2008, 2009; Mertens, 2009) developed the synergistic control concept, which combines the system identification power of engineering process control (EPC) with the monitoring power of SPC. Engineering process control is the discipline that encompasses all the activities that focus on mathematical modeling of (production) system dynamics.

Most automatic detection systems that have been developed for use on dairy farms focus on the detection of clinical mastitis (CM), as this is still the most fre- quent and costly disease in dairy production. Moreover, the detection of CM and abnormal milk is the critical success factor in AMS (Mollenhorst et al., 2012). Even though much research has been dedicated to this topic in the past decades, the quest for the perfect automated CM detection system continues (Hogeveen et al., 2010). The main cause of the continuing quest is the fact that traditionally insufficient time is spent analyzing the (complex) sensor data (Lehr, 2011). Based on this observation, Hogeveen et al. (2010) concluded that development of appropriate algorithms is a crucial part in the performance of a sensor system.

A simple parameter that can provide valuable information on the health of an individual cow is her milk yield (MY). This parameter is already measured on almost every modern dairy farm and its sensitivity to changes in animal health status has been reported by several researchers (de Mol and Ouweltjes, 2001; Edwards and Tozer, 2004; Nielsen et al., 2005; Lukas et al., 2009). Moreover, the effect of a disease on MY is often observed before the clinical diagnosis is made (Edwards and Tozer, 2004). The potential of MY as an early predictor of CM has been successfully tested (Deluyker et al., 1991; Lukas et al., 2009). Applying post hoc detection schemes that were based on milk yield data only, Lukas et al. (2009) found sensitivities of between 38.9 and $44.4 \%$ and specificities between 99.5 and $98 \%$. They concluded that such a system is simple and cheap and could alert the herd manager earlier of a nonspecific health problem.

As mentioned above, the real-time approach is crucial for practical use. The main goal of this study was to expand on the online synergistic control concept approach developed by Mertens et al. (2011) and apply it to dairy cow MY recorded at each milking session for the detection of CM. Finally, the synergistic control concept is evaluated for detection of abnormal deviations in MY caused by $\mathrm{CM}$ and compared with visual observation by the farmer.

\section{MATERIALS AND METHODS}

\section{Study Data Set}

Milk yield data from 2 AMS farms and 1 farm with a conventional milking system were used. The 2 robot farms, housing 55 and 120 cows, respectively, were equipped with 1 and 2 AMS (DeLaval) and were located in Flanders (Belgium). Amounts of milk were recorded using FloMaster milk meters (DeLaval). On the farm with 1 AMS, 168,392 milkings were recorded between November 21, 2005, and October 8, 2009. On the farm with 2 robots, 146,459 milkings were recorded between June 16, 2010, and November 3, 2011 (Table 1). 
Table 1. Descriptive statistics of the production and cow variables for the 3 different data sets [2 automatic milking system (AMS) farms and 1 conventional farm]

\begin{tabular}{|c|c|c|c|c|c|c|}
\hline \multirow[b]{2}{*}{ Item } & \multicolumn{2}{|c|}{$\begin{array}{c}\text { AMS farm } 1 \\
(\mathrm{n}=168,392)^{1}\end{array}$} & \multicolumn{2}{|c|}{$\begin{array}{l}\text { AMS farm } 2 \\
(\mathrm{n}=146,459)\end{array}$} & \multicolumn{2}{|c|}{$\begin{array}{l}\text { Conventional farm } \\
\quad(\mathrm{n}=112,636)\end{array}$} \\
\hline & Mean & $\mathrm{SD}$ & Mean & $\mathrm{SD}$ & Mean & $\mathrm{SD}$ \\
\hline Milkings per cow per day (no.) & 2.74 & 0.21 & 2.58 & 0.17 & 2.00 & \\
\hline DIM & 270.5 & 170.2 & 119.2 & 11.5 & 190.0 & 114.1 \\
\hline Lactation number & 1.76 & 0.94 & 2.38 & 1.47 & 2.42 & 1.54 \\
\hline Milk yield per milking $(\mathrm{kg})$ & 11.70 & 4.21 & 11.50 & 3.55 & 14.05 & 4.38 \\
\hline Time between milkings (p.m.) & & & & & 12.46 & 0.39 \\
\hline
\end{tabular}

${ }^{1}$ Number of recordings.

The farm with the conventional milking system, located in Wallonia (Belgium), milked 110 cows in a double 10 rapid-exit milking parlor (Index 90, Fullwood Ltd., Shropshire, UK). Milk production was measured by using AfiFlo milk meters (SAE Afikim, Kibbutz Afikim, Israel) and recorded daily from each milking by using Afimilk software (Afifarm version 3.01A, SAE Afikim; Table 1). The cows on all 3 farms were $100 \%$ Black and White and Red and White Holsteins.

Development of the early detection algorithm was done on the 2 AMS data sets. To validate the alarms produced by the CC detecting CM, the logbook of the conventional farm was used. Clinical mastitis events were detected by the farmer based on visual inspection of the presence of clots. The farmer used also electrical conductivity measurements (Afilab, SAE Afikim), with an attention list for increased conductivity (12-18\%) increasing with the lactation stage of the cow (i.e., increasing DIM). All 56 CM cases in the logbook in the period from February 19, 2010, to September 22, 2011, were followed by an intramammary antibiotic treatment, 5 were not analyzed because the start of the mastitis case was in the initializing period of the algorithm (see Online Trend Estimation section), and 2 cases were not taken into account because they occurred $<7 \mathrm{~d}$ after a treatment for mastitis, which means the cow was not fully recovered or the treatment was not effective enough. The last milking before milk was diverted from the bulk tank by the farmer was taken as the reference point for the visual detection of mastitis. Detection by the $\mathrm{CC}$ at that moment or milk yield registration was considered a detection, which equaled zero up to that point. The $49 \mathrm{CM}$ cases occurred, on average, after 138 DIM (Appendix Table A1). The prevalence of mastitis in the monitored period was $34 \%$.

\section{Synergistic Control Concept}

In the following sections, the synergistic control concept will be explained and described based on the case of milk weight, for cows milked in both AMS and conventional systems. In the first step, EPC was used to transform the nonstationary and autocorrelated MY data into normally distributed, stationary, and independent data. This time series was then introduced in a CC. The different steps involved in constructing the $\mathrm{CC}$ are schematically summarized in Figure 1.

\section{Engineering Process Control}

Individual MY recordings vary as a function of days in milk and parity. It is also known that milking frequency affects MY (Ouweltjes, 1998). Therefore, the measured MY values were standardized to remove the effect of time between milkings. In a second step, the observed lactation curve (nonstationary) was modeled and the model fit was removed from the observed data to obtain the residuals. Finally, the short-term correlation between subsequent measurements (autocorrelation) was captured with autoregressive moving average (ARMA) modeling and removed to obtain independent data. These different steps are explained in more detail below.

Data Standardization. The most important difference between automatic and conventional milking is that cows can be milked voluntarily in the former system. As a consequence, the variation in milking interval is greater on farms with an AMS (Hogeveen et al., 2001). This influence makes the MY between milkings not directly comparable. de Mol and Ouweltjes (2001) solved the problem by calculating the milk weight produced in the last $24 \mathrm{~h}$, replacing the original MY recording (the first standardization method). They used a linear function to model the cumulative yield between successive milkings. The second standardization method tested was to correct the original MY recording for the milking interval in which it was produced, resulting in MY production per hour $(\mathrm{kg} / \mathrm{h})$.

Lactation Modeling. A typical lactation curve can be described in 3 phases (Figure 2). The first phase 


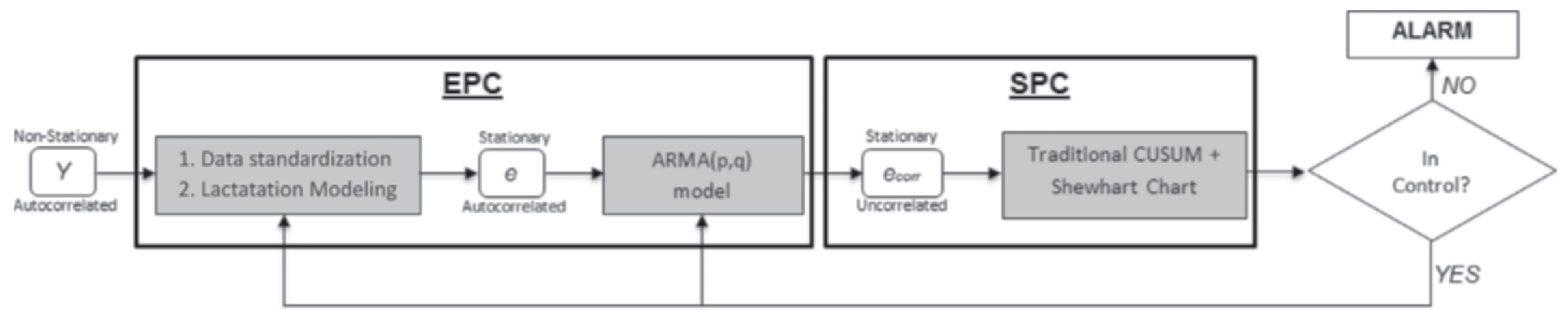

UPDATE MODEL PARAMETERS

Figure 1. Flowchart with the chronology of the different steps in building a cumulative sum (CUSUM) control chart for milk yield data (adapted with permission from Mertens, 2009). EPC = engineering process control; $\mathrm{SPC}=$ statistical process control; ARMA $=$ autoregressive moving average modeling; $Y=$ nonstationary, autocorrelated raw data; $\theta=$ stationary, autocorrelated data; $\theta$ corr $=$ stationary, uncorrelated and independent data.

starts after calving, with the initial milk yield increasing to a maximum or peak yield; the second phase is the period in which peak yield is maintained; and the third phase is the decrease from the peak yield to the end of lactation (Grossman and Koops, 2003). It is easily seen that lactation is not stationary, hence violating the first assumption of a classical CC. To achieve stationarity, the fitted lactation curve is subtracted from the observed data so that stationary residuals are obtained.

To deal with the issue of nonstationarity, the synergistic control concept procedure (Mertens, 2009; Mertens et al., 2009) involves a description of MY variation as a function of time by means of (non)linear models. Several models have been suggested for describing a lactation curve (Dijkstra et al., 1997; Grossman and Koops, 2003; Val-Arreola et al., 2004; Dematawewa et al., 2007). The mechanistic Dijkstra (DJ) model contains 4 coefficients and describes the patterns of mammary growth (cell proliferation and death) of mammals throughout pregnancy and lactation (Dijkstra et al., 1997). The multiphasic (MULT) model, developed by Grossman and Koops (2003), consists of 12 model coefficients and describes the lactation curve in 4 parts. The increasing phase is modeled by an increasing logistic function followed by the decreasing phase, which is further divided into 3 logistic functions. Val-Arreola et al. (2004) reported the best results for the DJ model, whereas Dematawewa et al. (2007) obtained the lowest prediction errors for the extended lactations for first, third, and greater than third parities with the MULT model. However, Dematawewa et al. (2007) recommend the DJ model if a mechanistic interpretation is required. Therefore, both the MULT and DJ models were used in this study to predict MY at every milking, based on the previously registered MY. The equations for these models are summarized in Table 2.

Online Trend Estimation. A recursive modeling approach with an initialization period of 14 standardized milk recordings was used. In this initializing period, the individual coefficients of the MULT and DJ models were estimated based on the trust-region method (Coleman and Li, 1996). After this initial step, every new measurement was compared with the value predicted by the model. Only if this new data point was considered "in control," which is checked in the SPC step, were the parameters of the model updated, as proposed by Mertens et al. (2009).

A weighting filter is used to progressively downweigh the influence of older data as these become less representative for the current situation. For the 4 combinations of standardization method and lactation model, goodness-of-fit measures were calculated. Accuracy was evaluated by comparing the following measures: the mean relative percentage deviation modulus $(\mathrm{P})$, the root mean square error (RMSE), and the adjusted coefficient of determination $\left(\mathrm{R}_{\text {adj }}^{2}\right)$, which are calculated as follows:

$$
\begin{gathered}
\mathrm{P}(\%)=\frac{100}{N} \cdot \sum \frac{\left|y_{i}-\hat{y}_{i}\right|}{y_{i}}, \\
\mathrm{RMSE}=\sqrt{\frac{1}{N} \sum\left(y_{i}-\hat{y}_{i}\right)^{2}}, \\
\mathrm{R}^{2} \text { adj }=1-\left(\frac{N-1}{N-p}\right) \frac{\sum\left(y_{i}-\hat{y}_{i}\right)}{\sum\left(y_{i}-\bar{y}_{i}\right)},
\end{gathered}
$$

with $y_{i}$ is the MY observation on milking $i, \hat{y}_{i}$ is the predicted MY for milking $i, \bar{y}$ is the average MY over the whole period, $N$ is the total number of recordings, and $p$ is the number of coefficients in the model.

ARMA Modeling. After subtracting the global trend by means of the online modeling procedure, the in-control residuals are checked for presence of a residual trend as autocorrelation. It is generally known that such a residual pattern (autocorrelation structure) is harmful to the performance of the cumulative sum 
Table 2. Equations used to model the lactation curves

\begin{tabular}{ll}
\hline Lactational model $^{1}$ & Functional form $^{2}$ \\
\hline Dijkstra (DJ) & $Y_{t}=a \cdot \exp \left[b\left(1-e^{c t}\right) / c-d t\right]$ \\
Multiphasic (MULT) & $\left.Y_{t}=a\left\{1 /\left[1+e^{-(t-c) b}\right]-p /\left[1+\left(0.5 e^{-(t-g) / d}\right)^{2}\right]-q /\left[1+e^{-(t-k) / h}\right)\right]-(1-p-q) /\left[1+\left(0.5 e^{-(t-k) / j}\right)^{2}\right]\right\}$ \\
\hline
\end{tabular}

${ }^{1}$ Dijkstra model: Dijkstra et al. (1997); multiphasic model: Grossman and Koops (2003).

${ }^{2}$ Where $Y_{t}$ is milk weight $(\mathrm{kg})$ in function of time $t ; a, b, c, d, g, h, i, j$, and $k$ are the parameters defining the shape of the individual curve; and $p$ and $q$ also define the individual curve. The representation of this model was done as in Dematawewa et al. (2007).

(cusum) CC (see Cusum Control Chart section). A lagone autocorrelation, or the influence of a measurement on the next measurement of 0.25 or higher increases the false alarm rate of the CC significantly (Montgomery, 2009). To model the autocorrelation in the residuals after standardization and trend modeling, an ARMA model is used. An ARMA model consists of 2 parts: autoregressive (AR) and moving average (MA). In an AR model, an observation at time $t$ depends on previous observations, whereas the MA model represents the process in a finite weighted sum of the random error term (Del Castillo, 2002; Montgomery et al., 2008; Montgomery, 2009).

The online trend estimation is constructed in a way that only the new data points that are in control have influence on the updated model coefficients. Although it might be possible to have no missing values in the observations and no out-of-control points, the aim of the proposed system is to find out-of-control points. Therefore, the trend estimation and ARMA modeling must be able to deal with missing values in the time series. For such cases, Jones (1980) suggested a maximum likelihood estimation (MLE) approach to ARMA modeling.

\section{Statistical Process Control}

The monitoring of the process was performed by means of CC, a well-known tool in SPC (Mertens, 2009). In a CC, the measured characteristics are plotted as a function of time or sample number. The chart also contains 3 other lines: the center line denotes the mean value or expected value of the measured variable; the other 2 horizontal lines are the upper and lower control limits. The values of the control limits (CL) are chosen as such that the probability to acquire measured values outside the CL is sufficiently low while the process is still in control (Montgomery, 2009). As a result, the width of the CL determines the trade-off between false-positive alarms (type I error) and false-negative alarms (type II error). A false-positive alarm occurs when a measurement values outside the CL is obtained while the process is still in control. A false-negative alarm occurs when an out-of-control process does not immediately result in an observation outside the CL. As different costs are usually related to the 2 types of errors, their cost should be taken into account when setting up the CC (de Vries and Reneau, 2010; Mertens et al., 2011).

The calculation of the CL depends on the type of CC used and is described below for each CC. The CC used in this work were the cusum and Shewhart CC. Both charts are available for normal, binomial, and gamma probability distributions (Montgomery, 2009). The combination of these 2 is ideal for the detection of small and large process deviations (Montgomery, 2009).

Shewhart Control Chart. Shewhart charts are specially designed for the detection of large process shifts ( $>3$ standard deviations, $\boldsymbol{\sigma})$ but are insensitive to smaller process changes $(\leq 1.5 \sigma)$. The CL are traditionally set at $\pm 3 \sigma$ from the center line, giving an in-control zone of $6 \sigma$.

Cusum Control Chart. The cusum CC is designed for detecting smaller process shifts $(<1.5 \sigma)$, which typically occur in biological processes (Devor et al., 1992; Montgomery, 2009). The cusum CC consists of 2 calculations: the first accumulates the deviations above the target value $T$ that exceed a certain reference value $K$ and is named the upper cusum, $C^{+}$. The lower cusum, $C^{-}$, accumulates the deviations below the target $T$ that exceed $K$. They are computed as follows:

$$
\begin{aligned}
C_{t}^{+} & =\max \left[0, x_{t}-(T+K)+C_{t-1}^{+}\right] \text {and } \\
C_{t}^{-} & =\max \left[0,(T-K)-x_{t}+C_{t-1}^{-}\right],
\end{aligned}
$$

with starting values $C_{0}^{+}=C_{0}^{-}=0 ; x_{t}$ is the observation at time $t ; T$ is the target value; $K=k \cdot \sigma_{0}$ (the reference value), and $\sigma_{0}$ is the in-control standard deviation of the time series. The process will be out of control when the upper or lower cusum crosses the CL $H=h \cdot \sigma_{0}$, where $h$ is the decision interval.

The performance of the cusum chart depends on the multiplication factors $k$ and $h$. To detect mastitis, the $k$ and $h$ values need to be set to detect the corresponding shift with high accuracy while generating a minimum 
A. Milk production: AMS

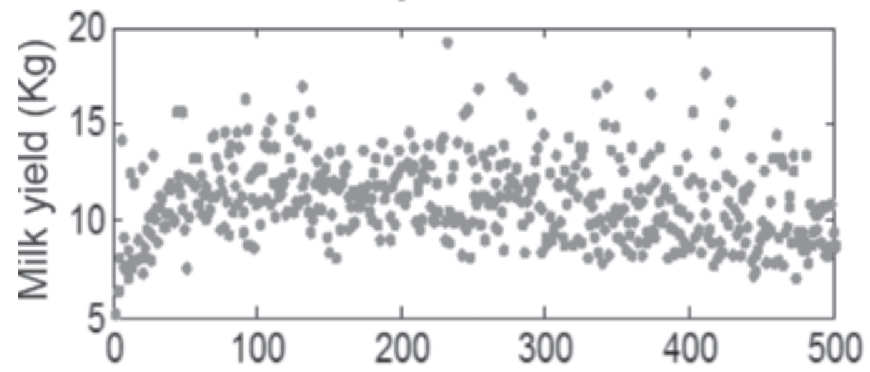

C. Standardized milk production: AMS

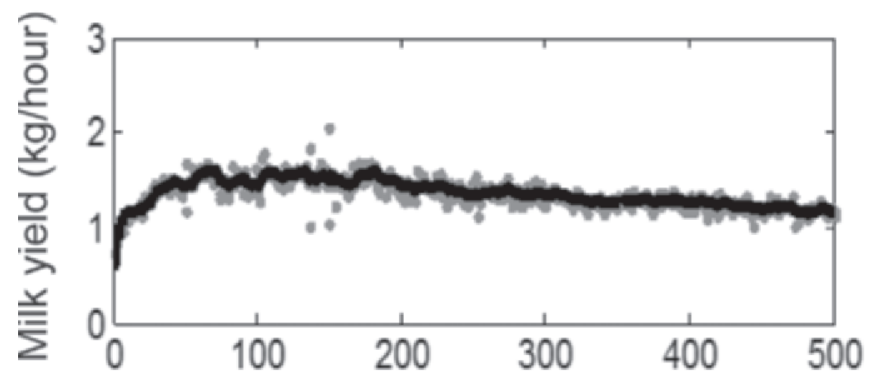

E. Prediction errors: AMS

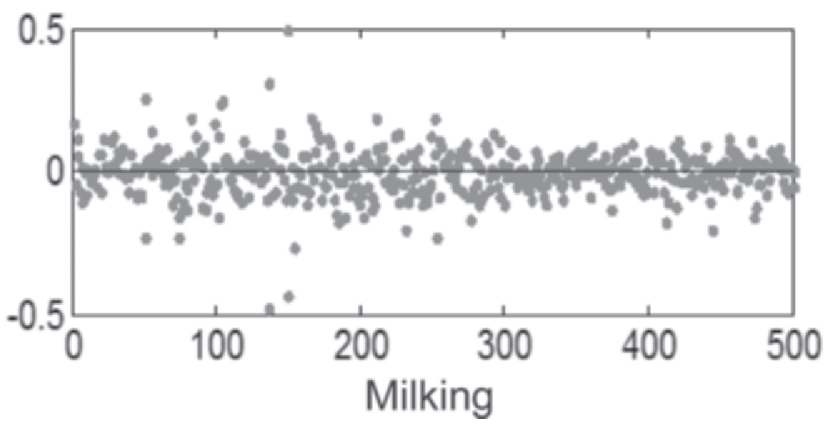

B. Milk production: parlor

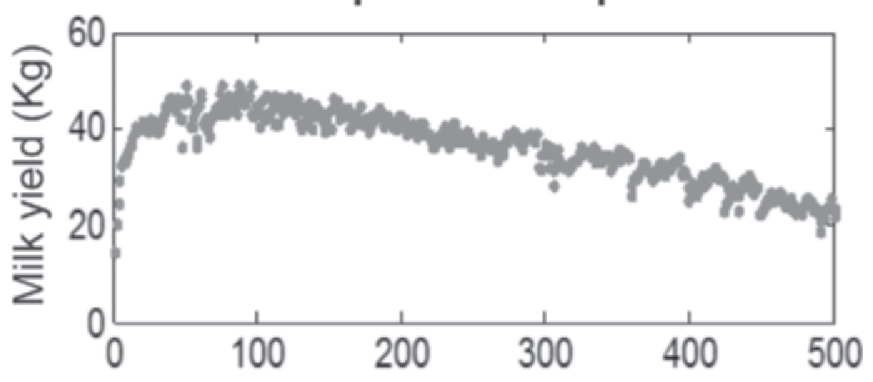

D. Standardized milk production: parlor

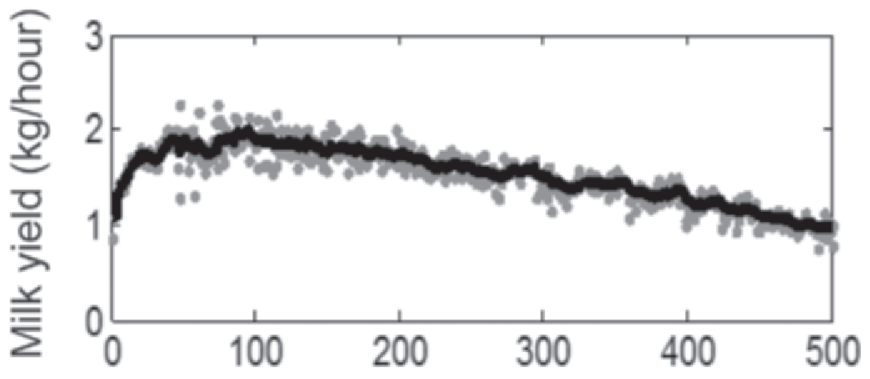

F. Prediction errors: parlor

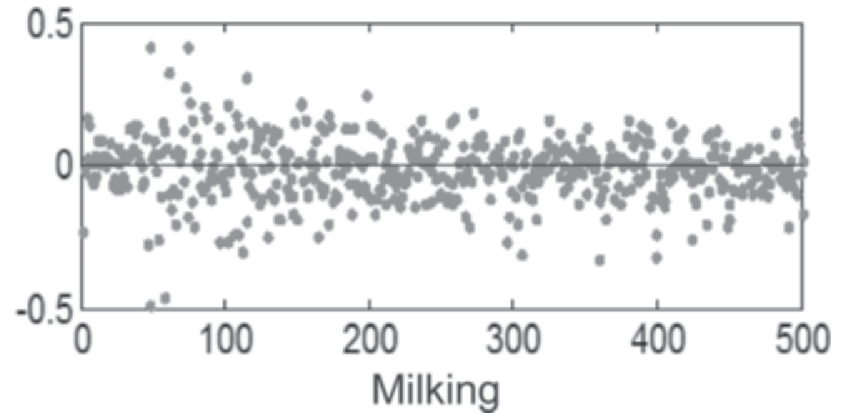

Figure 2. The first 2 steps of engineering process control (EPC) — standardization and modeling — to obtain stationary residuals for the 2 types of raw data. A, B: raw milk yield data of a cow milked in an automatic milking system (AMS) and parlor; C, D: raw data are standardized to milk yield in kilograms per hour and lactation trend is modeled (black line); E, F: residuals, which are stationary and can be used in statistical process control.

number of false alarms. This is quantified by the incontrol average run length $\left(\mathbf{A R L}_{\mathbf{0}}\right)$, an indication of the average time (or number of samples) between 2 false-positive alarms. The second measure is the average time between a process shift and its detection and is denoted by the out-of-control ARL $\left(\mathbf{A R L}_{1}\right)$. The $\mathrm{ARL}_{1}$ needs to be as short as possible, whereas $\mathrm{ARL}_{0}$ should be as long as possible. According to Lukas et al. (2009), CM has a mean negative effect of $2.0 \mathrm{~kg} / 24$ $\mathrm{h}$ and could be detected up to $4 \mathrm{~d}$ before diagnosis. Clinical mastitis was defined as a case where abnormal milk was detected. We estimated that it is acceptable for high-producing cattle to have a false alarm once a month. Based on an average value of 2.6 milkings/d for cows in an AMS, the $\mathrm{ARL}_{0}$ was set at 156 milkings. By setting $\mathrm{ARL}_{0}$ of 156 and the desired shift to detect at $2.0 \mathrm{~kg} / 24 \mathrm{~h}, k$ and $h$ values of 0.5 and 3.23 , respectively, were calculated by using ANYGETH software (http:// www.stat.umn.edu/cusum/software.htm; School of Statistics, University of Minnesota, St. Paul; Hawkins and Olwell, 1998).

\section{RESULTS AND DISCUSSION}

\section{Standardization, Trend Modeling, and ARMA Modeling}

Goodness-of-fit measures for the DJ and MULT lactation models applied to the MY data obtained with 
Table 3. Goodness-of-fit test results ${ }^{1}$ for Dijkstra and multiphasic models combined with the standardization methods

\begin{tabular}{lcc}
\hline & \multicolumn{2}{c}{ Model $^{2}$} \\
\cline { 2 - 3 } Method & Dijkstra & Multiphasic \\
\hline Method 1: 24-h standardization & 3.8583 & 3.5714 \\
P & 1.2145 & 1.1407 \\
RMSE & 0.8244 & 0.8224 \\
R ${ }^{2}$ adj & 4.539 & 4.1834 \\
Method 2: Milk production/h & 0.079 & 0.0788 \\
P & 0.8177 & 0.818 \\
RMSE & \multicolumn{2}{c}{${ }^{2}$ adj } \\
${ }^{1} \mathrm{P}=$ mean relative percentage deviation modulus; RMSE $=$ root mean \\
square error; R ${ }^{2}$ adj = adjusted coefficient of determination. \\
${ }^{2}$ Dijkstra model: Dijkstra et al. (1997); multiphasic model: Grossman \\
and Koops (2003).
\end{tabular}

both standardization methods are summarized in Table 3 .

The DJ and MULT models had adjusted coefficients of determination $\left(\mathrm{R}^{2} \mathrm{Adj}\right)$ of 0.8244 and 0.8224 , respectively, for standardization method 1 , and $\mathrm{R}^{2} \mathrm{Adj}$ of 0.8177 and 0.8180 for standardization method 2 . The difference in the accuracy of the different models for estimating milk weight per milking was not significant, which confirms the conclusion of Dematawewa et al. (2007) and the recommendation for smaller models with comparable accuracy. After removing the long-term pattern by the DJ recursive trend model, stationarity was achieved (Figure 2, panels E and F). The different standardization methods did not affect estimation accuracy but did affect the autocorrelation structure of the residuals. A sawtooth pattern was observed in the autocorrelation structure of the cows milked twice a day. This was because the interval between 2 milkings is not constant. On this farm, the time between evening and morning milkings was longer than that between morning and evening milkings. When the second standardization method $(\mathrm{kg} / \mathrm{h})$ was used, the lag-one autocorrelation was considerably lower (Figure 3). Thus, the most suitable EPC combined the DJ model with the second standardization method.

\section{Performance}

After removing the long-term trend modeled with the DJ model from the milk yield data from the farm with conventional milking parlor (standardized to $\mathrm{kg} / \mathrm{h}$ ), the residuals were plotted in the Shewhart and cusum CC with the higher defined control limits. The generated alarms were then compared with the notes in the farmer's logbook to evaluate the performance of the system. This evaluation was based on sensitivity and specificity. Sensitivity was defined as the percentage of CM cases

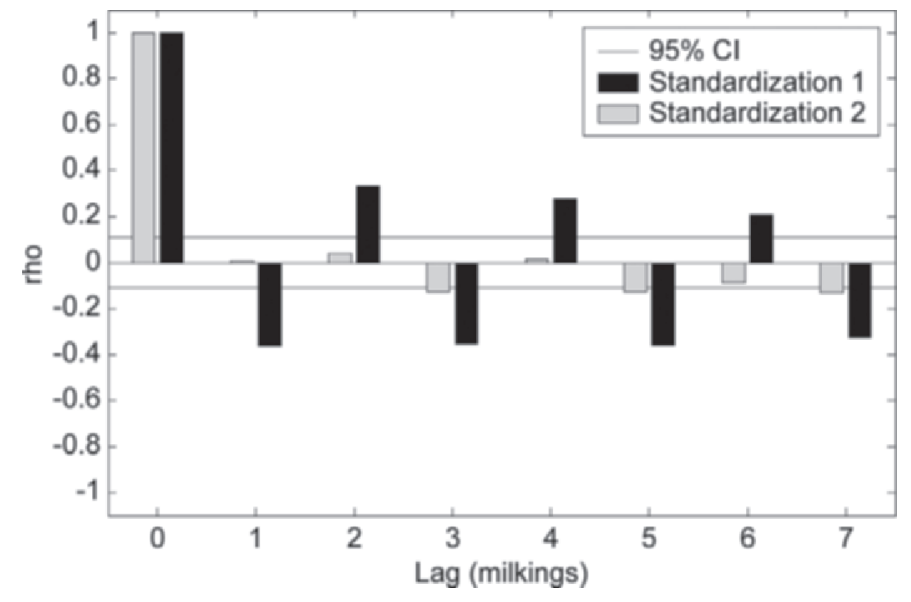

Figure 3. Example of the autocorrelation structure of the residuals of a cow milked 2 a times day and the different standardization methods (standardization method $1=24$-h production; standardization method $2=\mathrm{kg} / \mathrm{h}$ production). rho $=$ autocorrelation.

detected before or at the same time as diagnosis by the farmer, and specificity was defined as the percentage of milkings correctly classified as healthy.

Sensitivity. Of the 49 mastitis cases, 31 cases were detected by the proposed methodology at the same time or earlier than they were detected by the farmer. On average, CM was detected by the CC 1 milking before the farmer detected it and up to $4 \mathrm{~d}$ or $(8$ milkings) in the best case. In Figure 4, the CC for cow 53 is illustrated. In this case, the synergistic control system gave an alarm 5 milkings before milk separation out of the bulk tank due to antibiotic use. This means that the change in MY caused by the early clinical stage of mastitis was detected 4 milkings in advance. However, in $18 \mathrm{CM}$ cases, no alarm was given before the farmer began treatment for CM. We cannot verify whether the system would have given an alarm at a later stage because separation of the milk out of the bulk tank by the farmer resulted in a recorded MY of zero.

Compared with the results of Lukas et al. (2009), where udder problems were also detected based on deviations in milk yield, the online control system presented in this study had a 9\% higher sensitivity. Hovinen and Pyörälä (2011) compared the results of automatic detection systems for CM reported by different researchers. Compared with the sensitivity of $63 \%$ in the current study, only 3 studies out of 6 mentioned showed better results based on one parameter. It should be noted, however, that when the detection system was based on one parameter, electrical conductivity was the most common, whereas MY was only taken into account in a multiple-parameter model in earlier research on the detection of mastitis. This makes it difficult to compare our results with those of the 

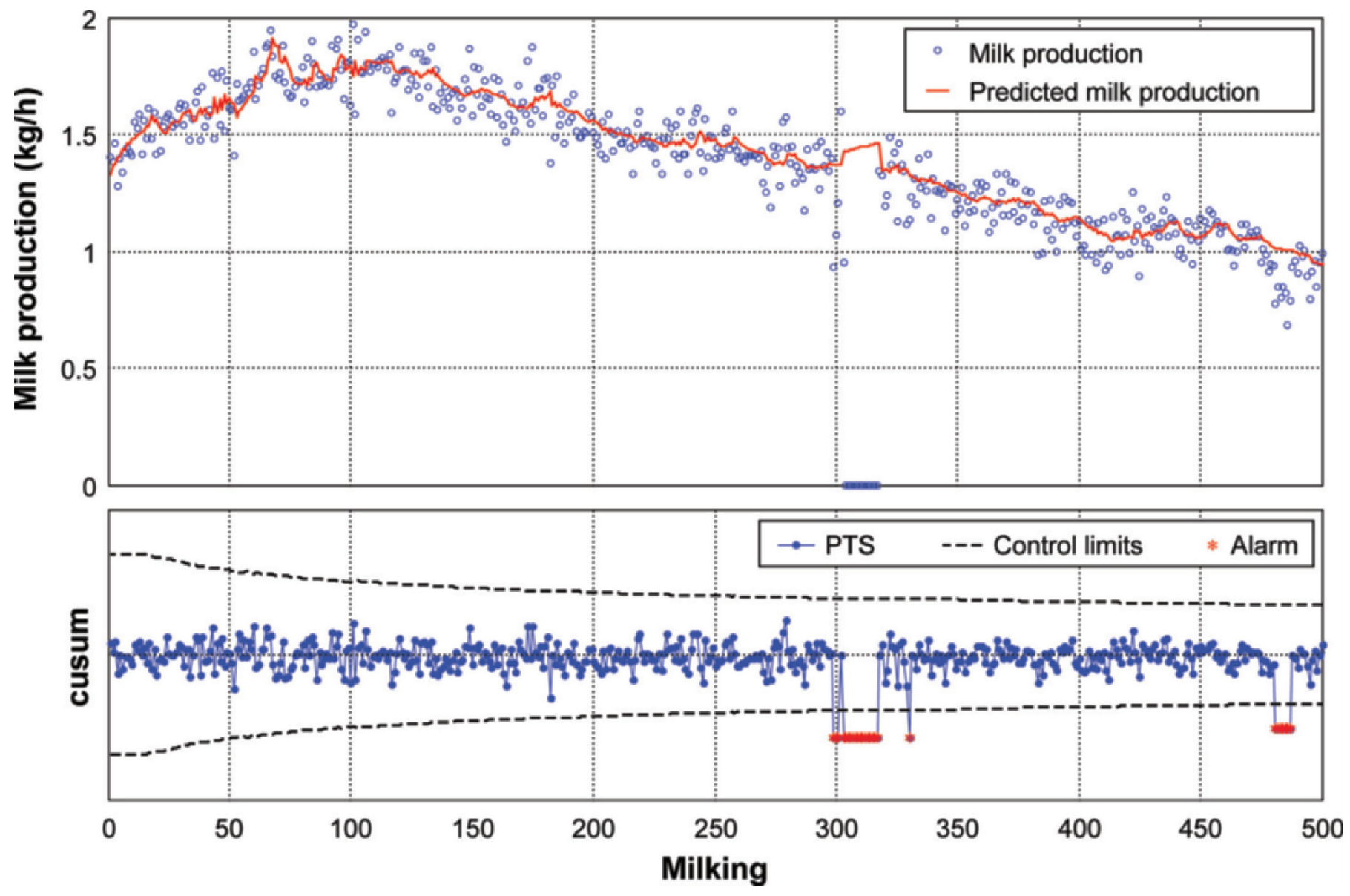

Figure 4. Control chart of milk yield of cow 53. Top: Course of the weighted milk yield standardized by method 1 and modeled by the Dijkstra model (Dijkstra et al., 1997). Bottom: cumulative sum (cusum) chart of the corrected residuals between measured value and predicted value based on the estimated trend. The red (alarm) points represent out-of-control observations. The farmer detected mastitis 1 milking before separation (milk yield $=0$ ), and the control chart detected a shift 4 milkings in advantage. PTS $=$ the change in upper and lower cusum. Color version available in the online PDF.

other studies. Moreover, the different studies show a large variability in sensitivity and number of cases on which the automatic detection system has been tested. Taking these considerations into account, sensitivity of $63 \%$ for automatic mastitis detection based solely on $\mathrm{MY}$ is considered very promising.

Specificity. Milk yield is not only affected by mastitis; for example, heat can also create a shift in MY (Bareille et al., 2003; Lukas et al., 2009). The desired detectable change in MY was $2.0 \mathrm{~kg}$ based on the research of Lukas et al. (2009). Of the other health events described by Lukas et al. (2009), 16 had effects larger than that caused by mild mastitis and thus would have been detected by the CC. In Figure 5, we illustrate detection by the CC of the negative effect of rumen acidosis on MY. The farmer treated the cow for acidosis at milking 153, but the effect on MY of the early acidosis or subclinical rumen acidosis was detected by the CC at milking 146 (8 milkings earlier). Because the logbook is incomplete in terms of recording all health events that could be detected, it is difficult to determine the specificity of this CC.

System Evaluation. The online synergistic control concept used here shows potential for dealing with inter- and intrasubject variability. The online and selflearning approach on MY (data that are available on most modern dairy farms) makes this system readily applicable in practice. Although the alarms derived from MY monitoring are nonspecific, they draw the attention of the farmer to a specific animal. This allows early detection and identification of the disease or problem, thus reducing the cost of treatment and minimizing the negative economic effect for the farmer and welfare effect for the animal (Lukas et al., 2009).

Sensitivity and specificity are very important when evaluating detection systems. Although this system could detect almost two-thirds of the mastitis cases in the current study, to be valuable, an automatic detec- 


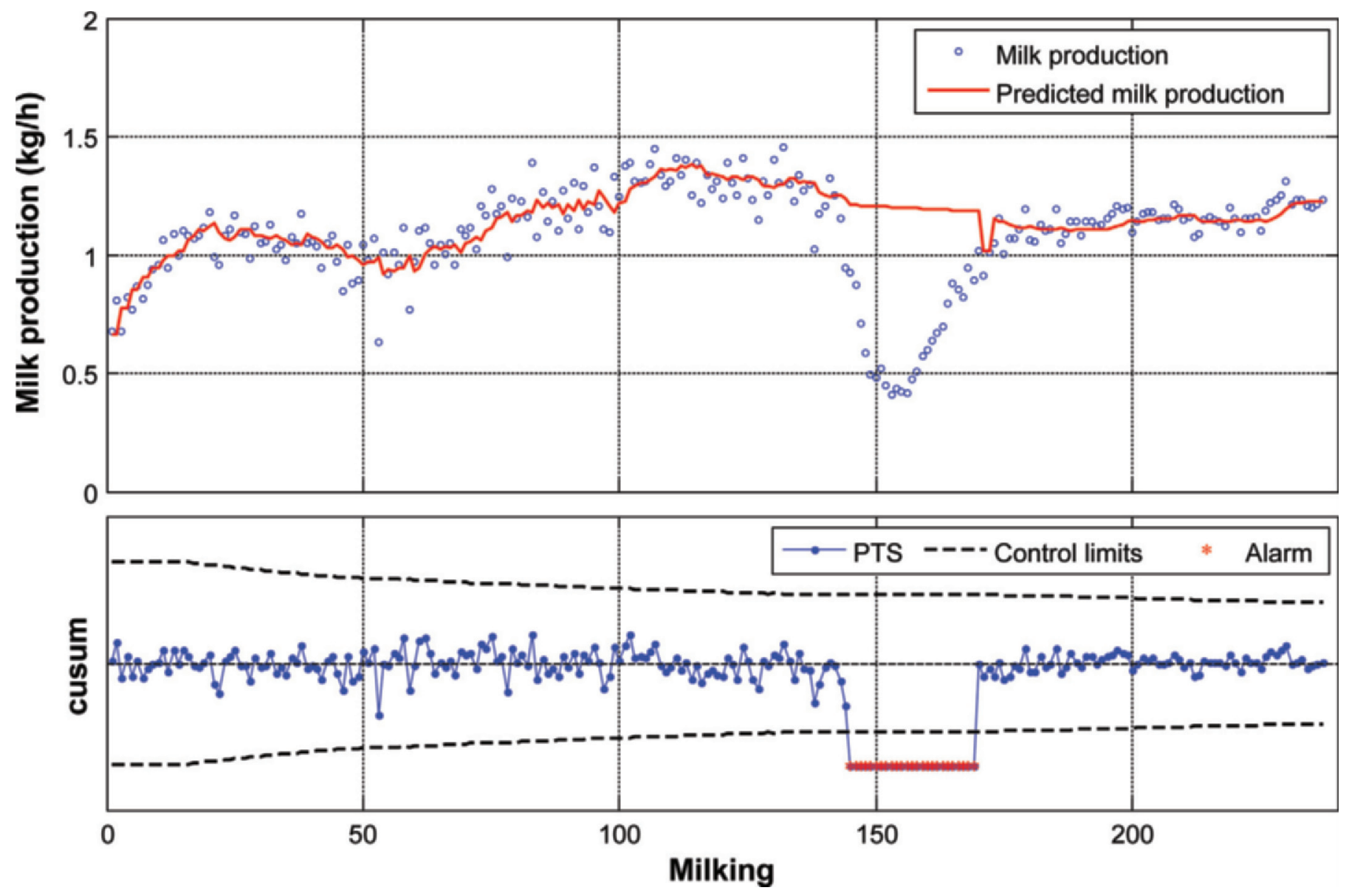

Figure 5. Control chart of milk yield of cow 93. Top: Course of the weighted milk yield standardized by method 1 and modeled by the Dijkstra model (Dijkstra et al., 1997). Bottom: cumulative sum (cusum) chart of the corrected residuals between measured value and predicted value based on the estimated trend. The red (alarm) points represent out-of-control observations. The farmer drenched the cow for acidosis at milking 153, and the effect of the disease was already detected by the control chart at milking 146. PTS = the change in upper and lower cusum. Color version available in the online PDF.

tion system should offer sensitivity of at least $80 \%$ and specificity of $99 \%$ (Hogeveen et al., 2010; Hovinen and Pyörälä, 2011). A possible reason why sensitivity of only $63 \%$ was reached in our study is the fact that not every CM case has the same effect on MY. The effect depends on several of factors, including parity, stage of lactation, pathogen type, and degree of infection. Thus, cases of $\mathrm{CM}$ occur that are not detected because the effect was smaller than the desired change for which the control chart was designed. Besides the fact that this system does not offer the required sensitivity, it also lacks specificity. Many health events can cause a sudden decrease in MY. A possible solution to improve the sensitivity and specificity is to account for multiple parameters in a multivariate approach (Hogeveen et al., 2010). Monitoring correlations between several production parameters, such as conductivity, activity, or milk content, could create more reliable information. This could be done by expanding the synergistic con- trol concept to all measurable dairy production parameters that can be accurately modeled. Another way to increase the performance of a detection system would be to monitor a more specific parameter that is related to only one disease or event (Chagunda et al., 2006).

Apart from the potential of extending this concept to other model parameters, model robustness could also be improved. Five mastitis cases occurred in the first 14 milk recordings (the initializing period) and they could not be detected. Mastitis occurs frequently in early lactation: around $25 \%$ of the CM cases in heifers, associated with all pathogens except Escherichia coli, were reported to occur in the first week of lactation (De Haas et al., 2002). By reducing the initialization period of the $\mathrm{CC}$, it might be possible to increase the detection rate without losing sensitivity. The same situation occurs after a health problem, when the cow recovers to a certain level of milk production. In this period, the model has to reinitialize itself before it can detect shifts 
in milk production; a second health problem occurring shortly after the first might be missed.

\section{CONCLUSIONS}

We presented a synergistic control concept method for applying CC to automatically detect health problems in dairy production. By applying this self-learning algorithm to MY data of individual cows, we showed that information on the cow's health status can be extracted from daily MY, a parameter that is already measured automatically on modern dairy farms. A sensitivity of $63 \%$ for detecting $\mathrm{CM}$, based on one parameter, indicates the potential of SPC in animal production. The synergistic control concept is a unique method to use SPC online and represents an important step towards its practical use. This technique could be expanded to all measurable parameters in dairy production that can be accurately modeled.

\section{ACKNOWLEDGMENTS}

The authors acknowledge the Institute for the Promotion of Innovation through Science and Technology (IWT-Vlaanderen, Flanders, Belgium) for their financial support. Bart De Ketelaere is financed by the Industrial Research Fund (Industrieel Onderzoeksfonds, IOF, Leuven, Belgium).

\section{REFERENCES}

Alwan, L., and H. Roberts. 1995. The problem of misplaced control limits. Appl. Stat. 44:269-278.

Bareille, N., F. Beaudeau, S. Billon, A. Robert, and P. Faverdin. 2003. Effects of health disorders on feed intake and milk production in dairy cows. Livest. Prod. Sci. 83:53-62.

Bewley, J. 2010. Precision dairy farming: Advanced analysis solutions for future profitability. Pages 1-8 in Proc. First North Am. Conf. Precision Dairy, Toronto, Canada. Progressive Dairy Operators, Guelph, ON, Canada.

Brandt, M., A. Haeussermann, and E. Hartung. 2010. Invited review: Technical solutions for analysis of milk constituents and abnormal milk. J. Dairy Sci. 93:427-436.

Chagunda, M. G. G., N. C. Friggens, M. D. Rasmussen, and T. Larsen. 2006. A model for detection of individual cow mastitis based on an indicator measured in milk. J. Dairy Sci. 89:2980-2998.

Coleman, T. F., and Y. Li. 1996. An interior trust region approach for nonlinear minimization Subject to bounds. SIAM J. Optim. 6:418-445.

de Haas, Y., H. W. Barkema, and R. F. Veerkamp. 2002. The effect of pathogen-specific clinical mastitis on the lactation curve for somatic cell count. J. Dairy Sci. 85:1314-1323.

De Ketelaere, B., K. Mertens, F. Mathijs, D. S. Diaz, and J. De Baerdemaeker. 2011. Nonstationarity in statistical process control-Issues, cases, ideas. Appl. Stochastic Models Data Anal. 27:367376.

de Mol, R. M., and W. Ouweltjes. 2001. Detection model for mastitis in cows milked in an automatic milking system. Prev. Vet. Med. 49:71-82.

de Vries, A., and B. J. Conlin. 2003. Design and performance of statistical process control charts applied to estrous detection efficiency. J. Dairy Sci. 86:1970-1984. de Vries, A., and J. K. Reneau. 2010. Application of statistical process control charts to monitor changes in animal production systems. J. Anim. Sci. 88(E. Suppl.):E11-E24.

Del Castillo, E. 2002. Statistical Process Adjustment for Quality Control. John Wiley \& Sons Inc., New York, NY.

Deluyker, H. A., J. M. Gay, L. D. Weaver, and A. S. Azari. 1991. Change of milk yield with clinical diseases for a high-producing dairy herd. J. Dairy Sci. 74:436-445.

Dematawewa, C. M. B., R. E. Pearson, and P. M. Vanraden. 2007. Modeling extended lactations of Holsteins. J. Dairy Sci. 90:39243936.

Deming, W. 1986. Out of the Crisis. Massachusetts Institute of Technology, Center for Advanced Engineering Study, Cambridge, MA.

Devor, R., T. Chang, and W. Sutherland. 1992. Statistical Quality Design and Control: Contemporary Concepts and Methods. Prentice Hall Inc., Upper Saddle River, NJ.

Dijkstra, J., J. France, M. S. Dhanoa, J. A. Maas, M. D. Hanigan, A J. Rook, and D. E. Beever. 1997. A model to describe growth patterns of the mammary gland during pregnancy and lactation. J. Dairy Sci. 80:2340-2354.

Edwards, J. L., and P. R. Tozer. 2004. Using activity and milk yield as predictors of fresh cow disorders. J. Dairy Sci. 87:524-531.

Grossman, M., and W. J. Koops. 2003. Modeling extended lactation curves of dairy cattle: A biological basis for the multiphasic approach. J. Dairy Sci. 86:988-998.

Hawkins, D., and D. Olwell. 1998. Cumulative Sum Charts and Charting for Quality Improvement. Springer-Verlag Inc., New York, NY.

Hogeveen, H., C. Kamphuis, W. Steeneveld, and H. Mollenhorst. 2010. Sensors and clinical mastitis - The quest for the perfect alert. Sensors (Basel) 10:7991-8009.

Hogeveen, H., and W. Ouweltjes. 2003. Sensors and management support in high-technology milking. J. Anim. Sci. 81:1-10.

Hogeveen, H., W. Ouweltjes, C. J. A. de Koning, and K. Stelwagen. 2001. Milking interval, milk production and milk flow-rate in an automatic milking system. Livest. Prod. Sci. 72:157-167.

Hovinen, M., and S. Pyörälä. 2011. Invited review: Udder health of dairy cows in automatic milking. J. Dairy Sci. 94:547-562.

Jones, R. 1980. Maximum likelihood fitting of ARMA models to time series with missing observations. Technometrics 22:37-41.

Lehr, H. 2011. Trying to define "practical and acceptable" precision livestock farming: Results from BrightAnimal. Pages 281-295 in Precision Livestock Farming '11. C. Lokhorst and D. Berckmans, ed. Czech Centre for Science and Society, Prague, Czech Republic.

Lukas, J. M., J. K. Reneau, R. Wallace, D. Hawkins, and C. MunozZanzi. 2009. A novel method of analyzing daily milk production and electrical conductivity to predict disease onset. J. Dairy Sci. 92:5964-5976.

Mertens, K. 2009. An intelligent system for optimizing the production and quality of consumption eggs based on synergistic control. $\mathrm{PhD}$ Thesis. Katholieke Universiteit Leuven, Heverlee, Belgium.

Mertens, K., E. Decuypere, J. De Baerdemaeker, and B. De Ketelaere. 2011. Statistical control charts as a support tool for the management of livestock production. J. Agric. Sci. 149:369-384.

Mertens, K., I. Vaesen, J. Löffel, B. Kemps, B. Kamers, J. Zoons, P. Darius, E. Decuypere, J. De Baerdemaeker, and B. De Ketelaere. 2009. An intelligent control chart for monitoring of autocorrelated egg production process data based on a synergistic control strategy. Comput. Electron. Agric. 69:100-111.

Mertens, K., I. Vaesen, J. Löffel, B. Ostyn, B. Kemps, B. Kamers, F. Bamelis, J. Zoons, P. Darius, E. Decuypere, J. De Baerdemaeker, and B. De Ketelaere. 2008. Data-based design of an intelligent control chart for the daily monitoring of the average egg weight. Comput. Electron. Agric. 61:222-232.

Mollenhorst, H., L. J. Rijkaart, and H. Hogeveen. 2012. Mastitis alert preferences of farmers milking with automatic milking systems. J. Dairy Sci. 95:2523-2530.

Montgomery, C. 2009. Introduction to Statistical Quality Control. 6th ed. John Wiley \& Sons Inc., Hoboken, NJ.

Montgomery, C., C. Jennings, and M. Kulahci. 2008. Introduction to Time Series Analysis and Forecasting. John Wiley \& Sons Inc., New York, NY. 
Nielsen, N. I., N. C. Friggens, M. G. G. Chagunda, and K. L. Ingvartsen. 2005. Predicting risk of ketosis in dairy cows using in-line measurements of beta-hydroxybutyrate: A biological model. J. Dairy Sci. 88:2441-2453.

Ordolff, D. 2001. Introduction of electronics into milking technology. Comput. Electron. Agric. 30:125-149.

Ouweltjes, W. 1998. The relationship between milk yield and milking interval in dairy cows. Livest. Prod. Sci. 56:193-201.
Rutten, C. J., A. G. J. Velthuis, W. Steeneveld, and H. Hogeveen. 2013. Invited review: Sensors to support health management on dairy farms. J. Dairy Sci. 96:1928-1952.

Shewhart, W. 1931. Economic Control of Quality of Manufactured Products. D. Van Nostrand, Princeton, NJ.

Val-Arreola, D., E. Kebreab, J. Dijkstra, and J. France. 2004. Study of the lactation curve in dairy cattle on farms in central Mexico. J. Dairy Sci. 87:3789-3799.

\section{APPENDIX}

Table A1. The 49 mastitis cases detected and time of occurrence

\begin{tabular}{|c|c|c|c|}
\hline $\begin{array}{l}\text { Date } \\
\text { (day/month/year) }\end{array}$ & Cow ID & DIM & Detection $^{1}$ \\
\hline $29 / 03 / 2010$ & 150 & 149 & No \\
\hline $18 / 04 / 2010$ & 6148 & 154 & No \\
\hline $23 / 04 / 2010$ & 97 & 185 & Yes \\
\hline $16 / 05 / 2010$ & 74 & 165 & Yes \\
\hline $25 / 05 / 2010$ & 120 & 213 & No \\
\hline $22 / 06 / 2010$ & 188 & 253 & No \\
\hline $21 / 07 / 2010$ & 46 & 253 & No \\
\hline $21 / 07 / 2010$ & 53 & 159 & Yes \\
\hline $22 / 07 / 2010$ & 150 & 264 & Yes \\
\hline 1/11/2010 & 151 & 58 & Yes \\
\hline $5 / 11 / 2010$ & 85 & 56 & Yes \\
\hline $11 / 11 / 2010$ & 95 & 52 & No \\
\hline $12 / 11 / 2010$ & 44 & 21 & Yes \\
\hline $19 / 11 / 2010$ & 109 & 22 & Yes \\
\hline $30 / 11 / 2010$ & 30 & 48 & No \\
\hline $2 / 12 / 2010$ & 136 & 71 & Yes \\
\hline $20 / 12 / 2010$ & 46 & 40 & No \\
\hline $26 / 12 / 2010$ & 145 & 99 & Yes \\
\hline $11 / 01 / 2011$ & 112 & 72 & Yes \\
\hline 14/01/2011 & 170 & 97 & Yes \\
\hline $14 / 01 / 2011$ & 189 & 110 & Yes \\
\hline $17 / 01 / 2011$ & 71 & 126 & No \\
\hline $17 / 01 / 2011$ & 76 & 126 & No \\
\hline $27 / 01 / 2011$ & 169 & 44 & Yes \\
\hline $16 / 02 / 2011$ & 49 & 116 & Yes \\
\hline $19 / 02 / 2011$ & 189 & 123 & Yes \\
\hline 28/02/2011 & 46 & 110 & Yes \\
\hline $7 / 03 / 2011$ & 150 & 127 & Yes \\
\hline $27 / 03 / 2011$ & 104 & 151 & Yes \\
\hline $8 / 04 / 2011$ & 20 & 48 & Yes \\
\hline $13 / 04 / 2011$ & 28 & 194 & Yes \\
\hline $2 / 05 / 2011$ & 97 & 34 & No \\
\hline $11 / 05 / 2011$ & 197 & 213 & No \\
\hline 19/05/2011 & 143 & 128 & Yes \\
\hline $5 / 06 / 2011$ & 20 & 106 & Yes \\
\hline $5 / 06 / 2011$ & 24 & 144 & Yes \\
\hline $6 / 06 / 2011$ & 178 & 271 & No \\
\hline $14 / 06 / 2011$ & 199 & 156 & Yes \\
\hline $16 / 06 / 2011$ & 54 & 191 & No \\
\hline $12 / 07 / 2011$ & 1451 & 269 & Yes \\
\hline 14/07/2011 & 188 & 275 & Yes \\
\hline $17 / 07 / 2011$ & 157 & 259 & No \\
\hline 20/07/2011 & 22 & 129 & No \\
\hline 23/08/2011 & 149 & 161 & No \\
\hline $27 / 08 / 2011$ & 63 & 263 & Yes \\
\hline $2 / 09 / 2011$ & 39 & 228 & No \\
\hline $15 / 09 / 2011$ & 149 & 184 & Yes \\
\hline $17 / 09 / 2011$ & 1321 & 17 & Yes \\
\hline $22 / 09 / 2011$ & 100 & 43 & No \\
\hline
\end{tabular}

${ }^{1}$ Yes $=$ detected by control chart; No = only detected by the farmer. 